\title{
Influence of Extrusion Speed on the Microstructure Evolution, Interface Bonding and Mechanical Response of Mg MB26/Al 7075 Composite Rod
}

\author{
Yu Chen ${ }^{1} \cdot$ Rui Zhang ${ }^{1} \cdot$ Tao Zhou $^{1} \cdot \mathrm{Li} \mathrm{Hu}^{1} \cdot \operatorname{Jian} \mathrm{Tu}^{1} \cdot \mathrm{Lai}^{-X i n ~ S h i}{ }^{1} \cdot$ Yan Zhi ${ }^{1} \cdot \mathrm{Li}^{-W e i} \mathrm{Lu}^{2} \cdot$ \\ Qiang Chen ${ }^{3,4} \cdot$ Ben-Hong Liao ${ }^{1} \cdot$ Lei Liu $^{1} \cdot$ Wen-Jun Ge ${ }^{1} \cdot$ Jing Xiao ${ }^{1} \cdot$ Ming-Bo Yang ${ }^{1}$
}

Received: 29 July 2018/Revised: 14 September 2018/Published online: 1 November 2018

(C) The Chinese Society for Metals and Springer-Verlag GmbH Germany, part of Springer Nature 2018

\begin{abstract}
The Mg MB26/Al 7075 composite rod, in which Mg MB26 serves as the sleeve and Al 7075 serves as the core, is fabricated via the process of co-extrusion. The influence of extrusion speed on the microstructure evolution, interface bonding and mechanical response of the $\mathrm{Mg} \mathrm{MB} 26 / \mathrm{Al} 7075$ composite rod is investigated. The results show that the typical extrusion texture of $\mathrm{Mg}$ sleeve does not change during co-extrusion; however, the average grain size in the $\mathrm{Mg}$ sleeve slightly changes from $1.57 \mu \mathrm{m}$ in the case of extrusion speed of $0.3 \mathrm{~mm} / \mathrm{s}$ to $2.78 \mu \mathrm{m}$ in the case of extrusion speed of $2.1 \mathrm{~mm} / \mathrm{s}$. The thickness of interface transition layer increases significantly from 5.5 to $50 \mu \mathrm{m}$, and therefore, the interface bonding becomes deteriorative with increasing extrusion speed; in particular, many cavities emerge in the case of 1.2 and $2.1 \mathrm{~mm} / \mathrm{s}$.
\end{abstract}

Keywords MB26/7075 composite rod · Extrusion speed · Microstructure evolution · Interface bonding · Mechanical response

\section{Introduction}

Magnesium $(\mathrm{Mg})$ alloys, as the lightest structural metallic material, have received considerable attention in the application of lightweight structural components in the

Available online at http://link.springer.com/journal/40195

Tao Zhou

zt19811118@cqut.edu.cn

$\triangle$ Jian Tu

tujian@cqut.edu.cn

$\triangle$ Qiang Chen

2009chenqiang@163.com

1 College of Material Science and Engineering, Chongqing University of Technology, Chongqing 400054, China

2 Institute of Light Metal Structural Materials, Hunan University of Science and Technology, Xiangtan 411201, China

3 Southwest Technology and Engineering Research Institute, Chongqing 400039, China

4 Precision Forming Integrated Manufacturing Technology of Collaborative Innovation Center, Chongqing 400039, China areas of automotive, telecommunication electronics, aerospace and other fields $[1,2]$. However, the disadvantages of low strength or poor formability based on limited active slip system availability (hexagonal close-packed, HCP structure) restrict their applications [3, 4]. In contrast, aluminum alloys have a wider range of applications owing to their excellent properties such as high specific strength, better ductility (face-centered cubic, FCC structure) and high thermal conductivity $[5,6]$. It has been reported that hybrid metal composite can effectively tailor mechanical properties such as strength, plasticity, impact capacity and abrasion resistance [7]. Therefore, $\mathrm{Mg} / \mathrm{Al}$ bimetal structure is a desirable lightweight composite benefiting from the advantages of both $\mathrm{Mg}$ and $\mathrm{Al}$ alloys. Consequently, it can improve the mechanical properties of $\mathrm{Mg}$ alloys without a dramatically increase in the weight of constructions or even attain inverse effects.

Various processing methods of fabricating $\mathrm{Mg} / \mathrm{Al}$ alloy composite have been developed such as roll bonding [8], accumulative roll bonding [9] and co-extrusion [10, 11] . Among these methods, co-extrusion is widely employed to manufacture $\mathrm{Mg} / \mathrm{Al}$ composite rods [10, 12-19]. Among those $\mathrm{Mg} / \mathrm{Al}$ composite rods, both the core constituent and 
sleeve component are mainly $\mathrm{Al}$ alloys and $\mathrm{Mg}$ alloys with low strength, such as Mg/Al [12-14, 16-19], AZ31/Al [15], AZ31/6063 [10] and AZ31/5052 [15]. It has been proved that the ductility of $\mathrm{Mg}$ constituent in composite rod can be improved owing to the addition of a pure $\mathrm{Al}$ core or sleeve, as compared to the monolithic $\mathrm{Mg} \operatorname{rod}[13,15]$. However, a low-strength $\mathrm{Al}$ core cannot effectively enhance the strength [12]. Hence, in order to achieve a significantly strengthening effect of $\mathrm{Mg}$ alloy rods, recently some other investigations have been conducted via using a high-strength $\mathrm{Al}$ alloy to strengthen a $\mathrm{Mg}$ alloy rod, e.g., AZ31/7050 [20-22]. It has been proved that a high-strength $\mathrm{Al}$ alloy core is beneficial to enhance the strength of $\mathrm{Mg} / \mathrm{Al}$ composite rods.

It is generally accepted that recrystallization behavior and microstructure evolution can be affected by the extrusion parameters including extrusion ratio, temperature and speed. Therefore, extrusion parameters have an influence on mechanical properties of the extruded materials [23, 24]. However, most reported works are mainly about the influence of extrusion parameters on the traditional extrusion process, and the influence on co-extrusion process of $\mathrm{Mg} / \mathrm{Al}$ composite rods has not been investigated previously. Therefore, in the present study a $\mathrm{Mg}$ alloy MB26/Al alloy 7075 composite rod with a high-strength Mg MB26 sleeve [25] an ultra-hard Al 7075 core [26] was successfully fabricated by co-extrusion at different speeds for elucidating the influence of extrusion speed on the microstructure evolution, interface bonding and mechanical response of Mg MB26/Al 7075 composite rods.

\section{Experimental}

\subsection{Fabrication of $\mathrm{Mg} / \mathrm{Al}$ Composite Rod}

The as-extrusion MB26 (Mg-Zn-Zr-RE) alloy and 7075 alloy were utilized in the present study; the chemical compositions of both alloys are listed in Table 1. As shown in Fig. 1, the $\mathrm{Mg} / \mathrm{Al}$ composite rod, in which $\mathrm{Mg}$ is the sleeve and $\mathrm{Al}$ is the core, was fabricated by co-extrusion. The Mg MB26 billet was machined into a hollow cup with an outer diameter of $80 \mathrm{~mm}$, a gauge length of $200 \mathrm{~mm}$, an inner diameter of $18 \mathrm{~mm}$ and a gauge length of $180 \mathrm{~mm}$. An Al 7075 cylinder with a diameter of $18 \mathrm{~mm}$ was cut, polished and fitted into the $\mathrm{Mg}$ hollow cup. The as-extrusion rods were kept in muffle furnace at $400{ }^{\circ} \mathrm{C}$ for $2 \mathrm{~h}$ to complete solid solution of $\mathrm{Al} 7075$; the billets and die were preheated at $430{ }^{\circ} \mathrm{C}$ and then immediately extruded at $320{ }^{\circ} \mathrm{C}$ with an extrusion ratio $25: 1$ and an extrusion speed of $0.3,0.7,1.2$ and $2.1 \mathrm{~mm} / \mathrm{s}$, respectively. Thereafter, the extruded rods were cooled at room temperature. The final extruded $\mathrm{Mg} / \mathrm{Al}$ rod has a diameter of $16 \mathrm{~mm}$ with an $\mathrm{Al}$ core of about $4.1 \mathrm{~mm}$ in diameter. Compression test along ED (extrusion direction) was performed at room temperature on a Shimadzu mechanical testing system with a consistent strain rate of $10^{-3} \mathrm{~s}^{-1}$. Moreover, each mechanical test was repeated three times. The compression samples for the $\mathrm{Mg}$ sleeve and $\mathrm{Mg} / \mathrm{Al}$ composite rod with respect to different extrusion speed were named as $\mathrm{Mg} / \mathrm{Al}-$ 0.3-Mg, $\mathrm{Mg} / \mathrm{Al}-0.7-\mathrm{Mg}, \mathrm{Mg} / \mathrm{Al}-1.2-\mathrm{Mg}$ and $\mathrm{Mg} / \mathrm{Al}-0.3$, $\mathrm{Mg} / \mathrm{Al}-0.7, \mathrm{Mg} / \mathrm{Al}-1.2$, respectively.

\subsection{Experimental Methods}

To check microstructure homogeneity, both the regions (regions A and B as shown in Fig. 1) close to the Al core of the specimens and near the surface were examined by an electron backscattered diffraction (EBSD) technique on a FEI Nova 400 SEM equipped with the HKL Channel 5.0 system. Samples for EBSD measurement were mechanically ground followed by electrochemical polishing in AC2 electrolyte. EBSD data were analyzed using the Channel 5 software.

X-ray diffraction (XRD) analysis was carried out using the Schulz reflection method with $\alpha$-angles ranging from $10^{\circ}$ to $90^{\circ}$, aiming at analyzing the phase composition of $\mathrm{Mg}$ or $\mathrm{Al}$ substrate in the samples. Morphology, thickness and element distribution of $\mathrm{Mg} / \mathrm{Al}$ interface were checked out by means of scanning electron microscopy (SEM) and energy-dispersive spectroscopy (EDS).

\section{Results and Discussion}

\subsection{Appearances of Mg/Al Composite Rod}

Figure 2 shows the surface profile of MB26/7075 composite rods in the case of different extrusion speeds. When the extrusion speed is relatively low, such as 0.3 and $0.7 \mathrm{~mm} / \mathrm{s}$, the surface of the rods is smooth without any defects. With increasing extrusion speed, cracks occur on the surface of the rods, especially at the high extrusion speed of $2.1 \mathrm{~mm} / \mathrm{s}$. The surface quality of the $\mathrm{Mg} / \mathrm{Al}$
Table 1 Chemical composition of the base metal in the test (mass fraction, \%)

\begin{tabular}{llllllllllll}
\hline Alloy & $\mathrm{Si}$ & $\mathrm{Fe}$ & $\mathrm{Cu}$ & $\mathrm{Mn}$ & $\mathrm{Mg}$ & $\mathrm{Cr}$ & $\mathrm{Zn}$ & $\mathrm{Ti}$ & $\mathrm{Al}$ & $\mathrm{Zr}$ & $\mathrm{RE}$ \\
\hline 7075 & $\leq 0.4$ & $\leq 0.5$ & $1.2-2.0$ & $\leq 0.4$ & $2.1-2.9$ & $0.018-0.28$ & $5.1-6.1$ & $\leq 0.2$ & $\mathrm{Bal}$. & - & - \\
MB26 & & & & & Bal. & & 5.9 & & & 0.6 & 1.0 \\
\hline
\end{tabular}




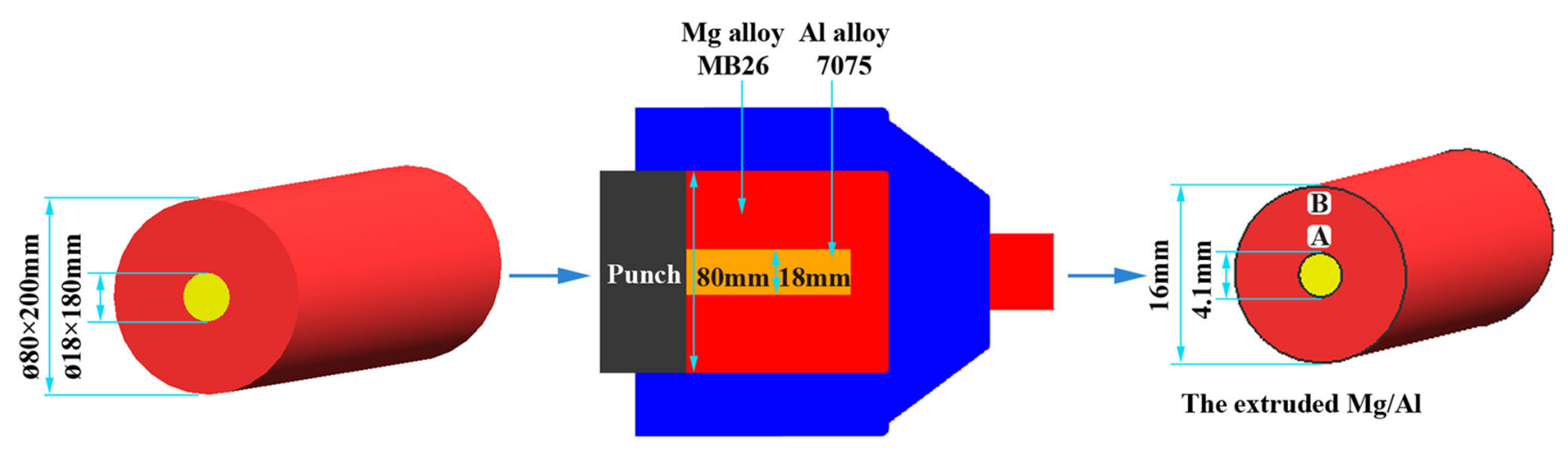

Fig. 1 Schematic diagrams of fabricating $\mathrm{Mg} / \mathrm{Al}$ composite rods by co-extrusion

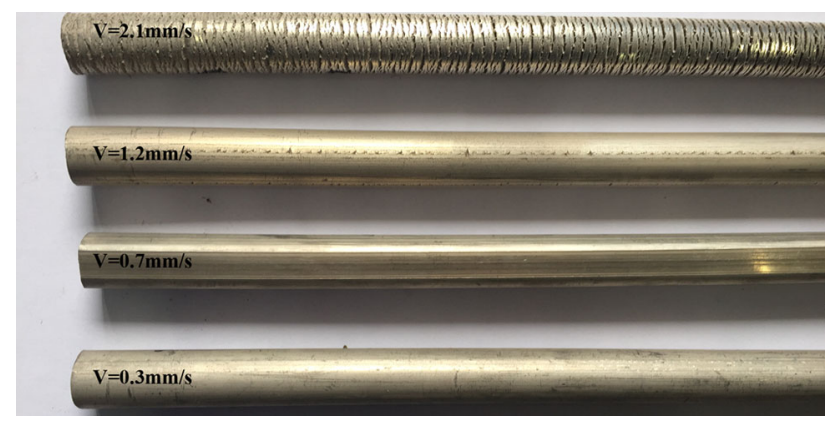

Fig. 2 Surface profile of extruded bars at different extrusion speeds

composite rods, obviously, becomes deteriorative with increasing extrusion speed. This observation has also been reported in the extruded rods of AZ80 alloy [27] and ZK60 alloy [28]. In multimaterial forming processes, material deformation patterns greatly depend on the flow stress ratio, and the $\mathrm{Al}$ core undergoes greater cross-sectional reduction than the $\mathrm{Mg}$ sleeve. Therefore, different flow velocities of the $\mathrm{Mg}$ sleeve and the $\mathrm{Al}$ core due to shear friction are supposed to be the main reason for the cracking of the $\mathrm{Mg}$ alloy sleeve. In the present study, with increasing extrusion speed, the difference in the flow velocities between $\mathrm{Mg}$ sleeve and $\mathrm{Al}$ core may be further increased, which leads to deterioration of surface quality.

\subsection{Microstructure and Texture}

Figure 3 shows the inverse pole figure maps and corresponding pole figures of the selected regions in the $\mathrm{Mg}$ sleeve of composite rods at various extrusion speeds. All the $\mathrm{Mg}$ sleeves show a bimodal microstructure, consisting of several elongated un-recrystallized grains, which are surrounded by large amounts of equiaxed fine recrystallized grains. The average grain size of the $\mathrm{Mg}$ alloy sleeves is about $1.6,1.8,1.7$ and $2.8 \mu \mathrm{m}$ at the extrusion speeds of $0.3,0.7,1.2$ and $2.1 \mathrm{~mm} / \mathrm{s}$, respectively. It means that, with increasing extrusion speeds, the grains of $\mathrm{Mg}$ alloy sleeves subtly coarsen. This observation is also akin to the results reported in [23, 27, 28]. The main reason can be explained that, an increase in strain rate, which serves to increase local heat generation due to plastic deformation [27], leads to the growth of the grains.

Moreover, as shown in Fig. 3, EBSD micrographs in both selected regions of $\mathrm{A}$ and $\mathrm{B}$ shown in Fig. 1 were examined. All regions show a typical texture, namely a sharp fiber with $c$-axis largely normal to the ED, which generates in all the extruded $\mathrm{Mg}$ sleeves at different extrusion speeds. Obviously, co-extrusion of MB26 (hard sleeve)/7075 (ultra-hard core) composite rod can hardly change the texture type of the $\mathrm{Mg}$ component, even at high extrusion speeds. Feng et al. [21, 22] also suggests that, in AZ31 (soft sleeve)/7075 (ultra-hard core) composite rod, the extruded AZ31 sleeve retains the typical texture. The main reason may be that the axisymmetrical friction stress surrounds with ED and approximately parallels to the direction that is between the rod and the die, even though a drastic friction stress exists at $\mathrm{Mg} / \mathrm{Al}$ interface during extrusion.

Figure 4 provides the XRD analysis of the Mg sleeve from composite rods. It is worth noting that at the extrusion speed of $0.3 \mathrm{~m} / \mathrm{s}$, the main phases in the $\mathrm{Mg}$ sleeve are $\alpha$ $\mathrm{Mg}, \mathrm{Mg}-\mathrm{Zn}, \mathrm{W}\left(\mathrm{Mg}_{3} \mathrm{Y}_{2} \mathrm{Zn}_{3}\right)$ and I phase (quasi-crystalline phase, $\mathrm{Mg}_{3} \mathrm{YZn}_{6}$ ). With increasing extrusion speeds, the types of all the main phases are not changed, indicating that extrusion speed hardly influences the phase composition of $\mathrm{Mg}$ substrate in the composite rods. It has been reported that particles such as I phase probably plays an important role in the nucleation of the new grains rather than the suppression of the grain growth, and $\mathrm{W}$ phase could impede the migration of sub-grain and high-angle grain boundary to some degree [29, 30], thereby causing high dislocation density and internal energy around the dispersed $\mathrm{W}$ phase produced by large amounts of deformation, which is favorable to nucleation of dynamically recrystallization [31]. Furthermore, large amounts of broken W phase, which is dispersed evenly in the interior of grains or grain boundaries in the $\mathrm{Mg}$ sleeve [28], can also suppress 

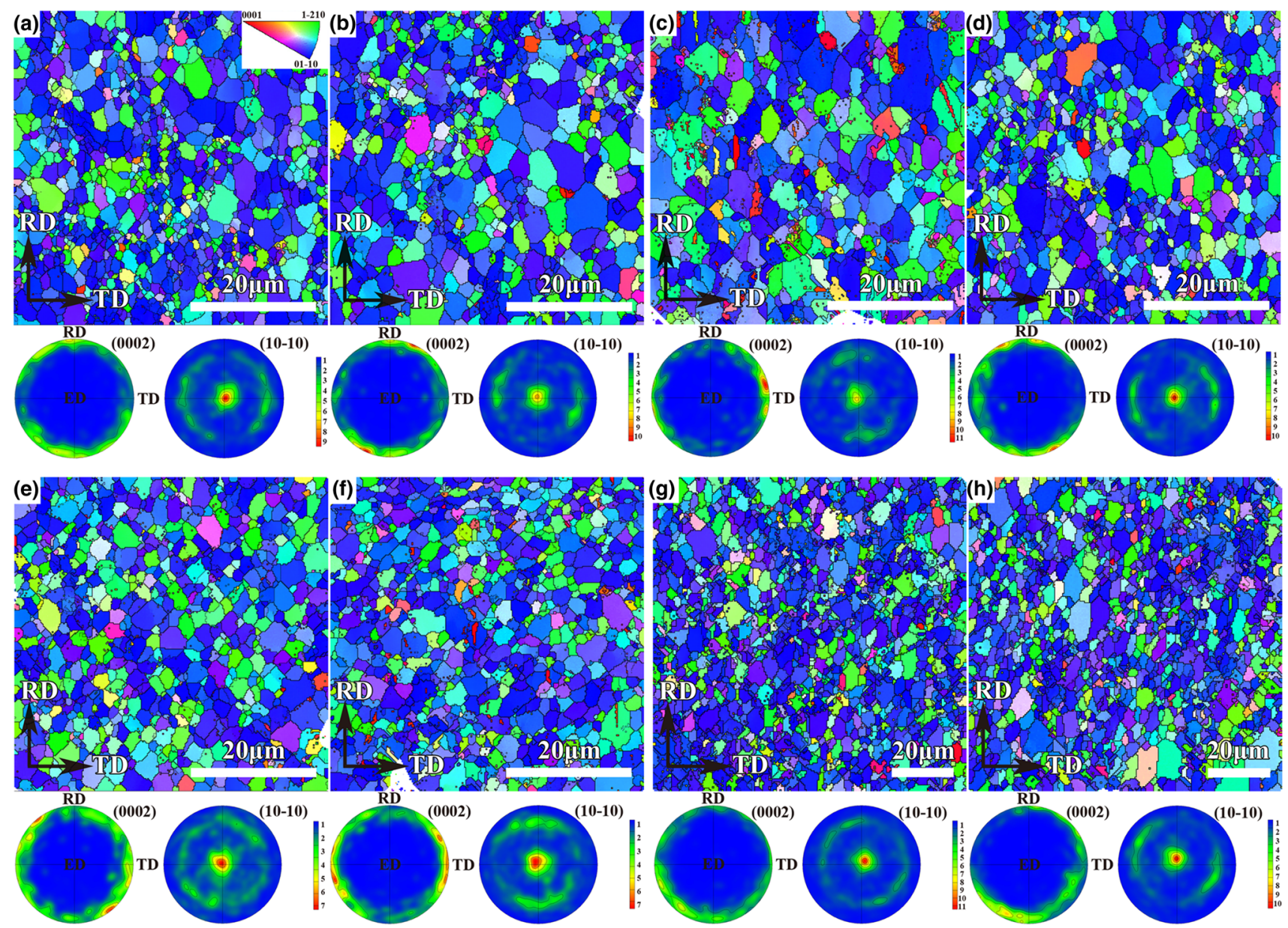

Fig. 3 Inverse pole figures and the corresponding pole figures of the selected regions at various speeds in the $\mathrm{Mg}$ sleeve in $\mathrm{Mg} / \mathrm{Al}$ composite rod: a, b $0.3 ; \mathbf{c}, \mathbf{d} 0.7 ; \mathbf{e}, \mathbf{f} 1.2 ; \mathbf{g}, \mathbf{h} 2.1 \mathrm{~mm} / \mathrm{s}$ (where a, c, e, $\mathbf{g}$ refers to region $\mathrm{A}, \mathbf{b}, \mathbf{d}, \mathbf{f}, \mathbf{h}$ is for region $\mathrm{B}$ )

the growth of recrystallized grains by retarding the migration of the grain boundaries [32]. Therefore, after hot co-extrusion, the fine grains can be obtained in the $\mathrm{Mg}$ sleeve, even at high extrusion speed.

\subsection{Interface Bonding}

Cross-sectional schematic SEM micrographs of the MB26/ 7075 composite rods are shown in Fig. 5. In the case of the extrusion speed of $0.3 \mathrm{~mm} / \mathrm{s}$, there is good interface bonding between the $\mathrm{Mg}$ sleeve and the $\mathrm{Al}$ core. With increasing extrusion speed, the interface bonding becomes deteriorative, which is accompanied by many cavities (marked with blue arrows) and the local melt of the interface metals. In order to further obtain the detailed information on interface bonding of MB26/7075 composite rods, SEM images and corresponding element line scanning obtained from cross section of the composite rods at various extrusion speeds are shown in Fig. 6. As the extrusion speed increases from 0.3 to $1.2 \mathrm{~mm} / \mathrm{s}$, the thickness of the transition layer increases significantly from
5.5 to $50 \mu \mathrm{m}$. It is well known that the diffusion layer is related to temperature and pressure. Temperature has a more crucial influence on the diffusion of atoms. The relation between diffusion coefficient and temperature can be defined as [33]:

$D=D_{0} \mathrm{e}^{-Q / R T}$,

where $D$ is diffusion coefficient, $D_{0}$ stands for diffusion constant, $Q$ refers to the diffusion activation energy, $R$ represents constant and $T$ is the absolute temperature. The thickness of interface diffusion layer is proportional to the diffusion distance, and the relationship between the distance $X$ and the diffusion time $t$ is [34]:

$X=k \sqrt{D t}$,

where $k$ is constant. In the present work, an increase in extrusion speed can lead to the rise in the temperature $T$ during the extrusion process, so the diffusion coefficient $D$ increases and further results in the increase in diffusion distance $X$. Therefore, with increasing extrusion speed, the thickness of interface diffusion layer increases. According 

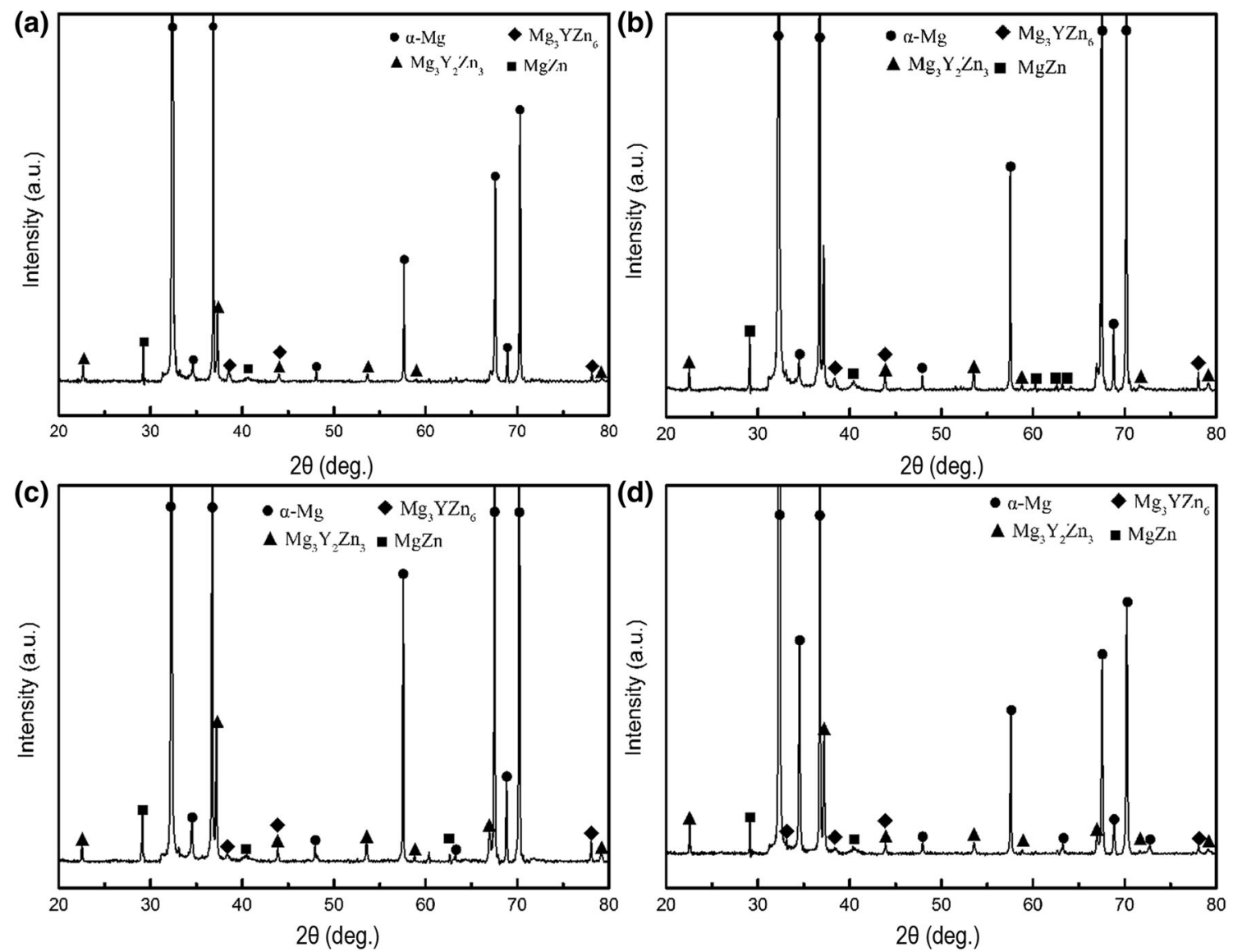

Fig. 4 X-ray diffraction patterns near the interface of $\mathrm{Mg}$ substrate in composite rod at different extrusion speeds: a $0.3 \mathrm{~mm} / \mathrm{s}, \mathbf{b} 0.7 \mathrm{~mm} / \mathrm{s}$, c $1.2 \mathrm{~mm} / \mathrm{s}, \mathbf{d} 2.1 \mathrm{~mm} / \mathrm{s}$

to the interface line scanning as shown in Fig. 6a-d, the concentration of $\mathrm{Mg}$ in the $\mathrm{Mg}$ sleeve is relatively high, and the element concentration gradient changed relatively smooth near the side of the $\mathrm{Mg}$ aside, while the content of Al is comparative small, and the concentration changed sharply near the side close to the $\mathrm{Al}$ aside. This indicates that there exists a clearly transition layer with a gradient element distribution of $\mathrm{Mg}$ and $\mathrm{Al}$ between two hybrid metals after co-extrusion [35]. It can be deduced that the sub-layer adjacent to $\mathrm{Mg}$, named as sub-layer 1, is mainly composed of $\mathrm{Mg}_{17} \mathrm{Al}_{12}$ phase and that next to $\mathrm{Al}$, named as sub-layer 2, contains $\mathrm{Mg}_{2} \mathrm{Al}_{3}$ phase [22].

As shown in Figs. 5d and 6c, d, with increasing extrusion speed, many cavities occur in the interface, especially in the sub-layer adjacent to $\mathrm{Mg}$, i.e., sub-layer 1. The main reason can be analyzed as follows. An increase in the extrusion speed can lead to the enhanced interfacial temperature [36]. According to the $\mathrm{Mg}-\mathrm{Al}$ phase diagram [11], the temperature of eutectic reaction $1 \quad(\mathrm{~L} \leftrightarrow \alpha$ $\mathrm{Mg}+\mathrm{Mg}_{17} \mathrm{Al}_{12}$ ) is about $437{ }^{\circ} \mathrm{C}$, which is lower than that of eutectic reaction $2\left(\mathrm{~L} \leftrightarrow \alpha-\mathrm{Mg}+\mathrm{Mg}_{2} \mathrm{Al}_{3}\right)$ that is about $450{ }^{\circ} \mathrm{C}$. So, with the interfacial temperature increasing, the intermetallic compound $\mathrm{Mg}_{17} \mathrm{Al}_{12}$ phase can be easier to melt than the $\mathrm{Mg}_{2} \mathrm{Al}_{3}$. Li et al. [37] also proved that the intermetallic compounds have melt $\left(\alpha-\mathrm{Mg}+\mathrm{L}-\mathrm{Mg}_{17} \mathrm{Al}_{12}\right.$ $\rightarrow \mathrm{L}$ ) before heating up to $450{ }^{\circ} \mathrm{C}$. As mentioned above, sub-layer 1 is mainly composed of $\mathrm{Mg}_{17} \mathrm{Al}_{12}$ phase, but sub-layer 2 contains $\mathrm{Mg}_{2} \mathrm{Al}_{3}$ phase. Thus, the cavities mainly appear in sub-layer 1 .

In addition, in the case of the extrusion speed of 0.3 and $0.7 \mathrm{~mm} / \mathrm{s}$, the thickness of sub-layer 2 is larger than sublayer 1, as shown in Fig. 6a, b. This observation may be due to the difference in the mutual diffusion coefficient of $\mathrm{Mg}$ and $\mathrm{Al}$ alloy. The diffusion coefficient of $\mathrm{Al}$ in $\mathrm{Mg}$ is $1.7 \times 10^{-4} \mathrm{~m}^{2} / \mathrm{s}$ and it is faster than that of $\mathrm{Mg}$ in $\mathrm{Al}$, which is $1.5 \times 10^{-4} \mathrm{~m}^{2} / \mathrm{s}$. This aspect results in the larger thickness of sub-layer 2 at the extrusion speeds of 0.3 and $0.7 \mathrm{~mm} / \mathrm{s}$. However, it should be noted that, as the extrusion speed up to 1.2 and $2.1 \mathrm{~mm} / \mathrm{s}$, sub-layer 1 becomes much thicker than sub-layer 2 , which is contrary to the results at relatively low extrusion speeds $(0.3$ and $0.7 \mathrm{~mm} /$ s). Moreover, the intermetallic compound $\mathrm{Mg}_{17} \mathrm{Al}_{12}$ phase with lower melting point can be easier to melt than the $\mathrm{Mg}_{2} \mathrm{Al}_{3}$ phase, which may also lead to the greater thickness 

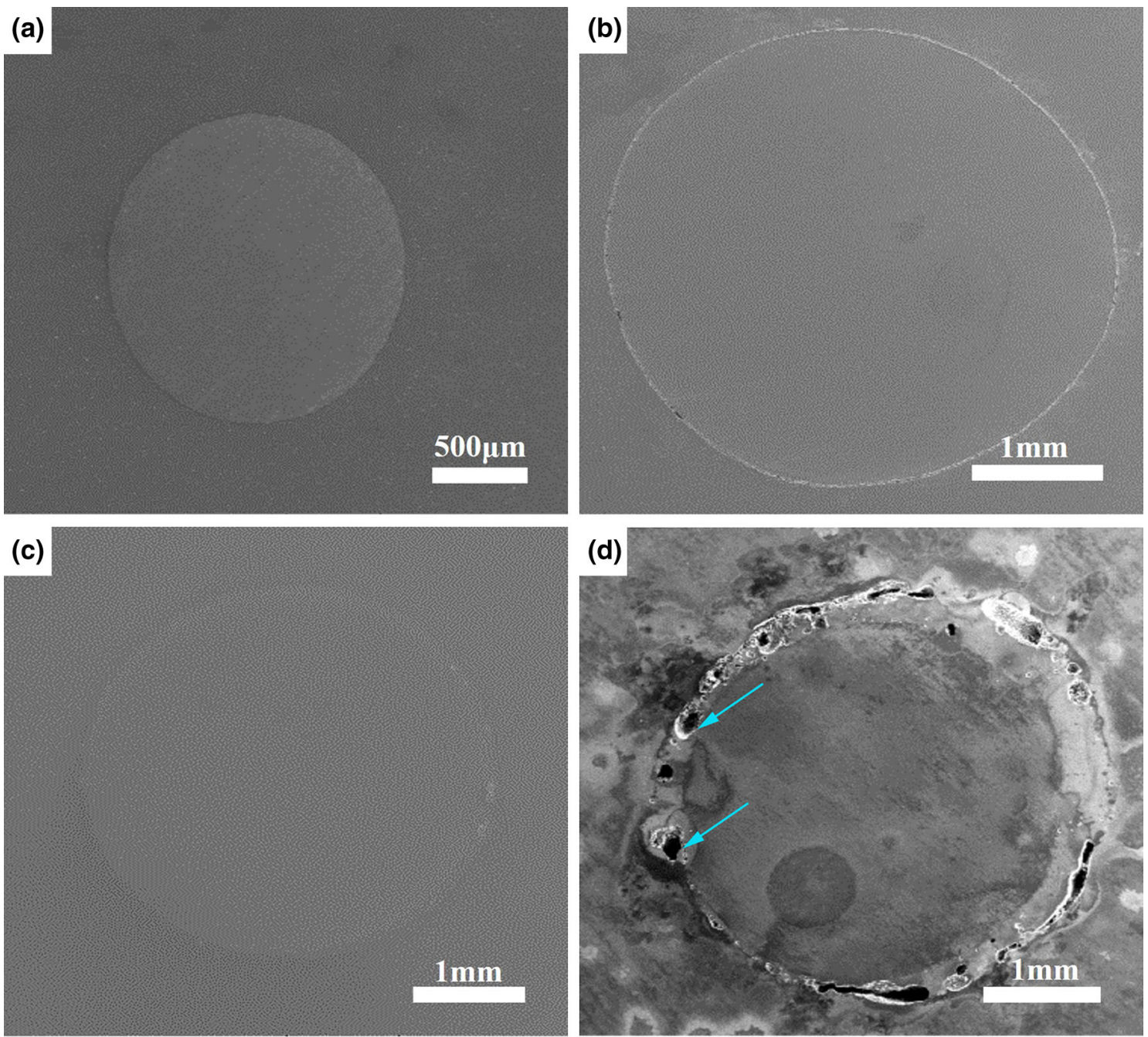

Fig. 5 Cross-sectional schematic SEM micrographs of the Mg/Al composite rods at various speeds: a $0.3 \mathrm{~mm} / \mathrm{s}, \mathbf{b} 0.7 \mathrm{~mm} / \mathrm{s}$, c $1.2 \mathrm{~mm} / \mathrm{s}$, d $2.1 \mathrm{~mm} / \mathrm{s}$

of sub-layer 1 than that of sub-layer 2 at high extrusion speed.

\subsection{Mechanical Response}

Figure 7 shows the strain hardening behaviors of the MB26 sleeve and the MB26/7075 composite rods with different extrusion speeds under compression along the ED. The engineering stress-strain curve of $\mathrm{Mg} / \mathrm{Al}$ composite rod exhibits an obvious plateau, which indicates the typical feature of predominant deformation $\{10-12\}$ tension twinning [38, 39]. Table 2 lists the compressive yield strength (CYS), ultimate compression strength (UCS) derived from the stress-strain curves, demonstrating that the CYS and UCS of the composite rods slightly decreased from 263 to $246 \mathrm{MPa}$ and from 470 to $453 \mathrm{MPa}$, respectively. By comparison with the $\mathrm{Mg}$ sleeve, the CYS of $\mathrm{Mg}$ / $\mathrm{Al}$ composite rod increased by 12,18 and $22 \mathrm{MPa}$ at the speed of $0.3,0.7$ and $1.2 \mathrm{~mm} / \mathrm{s}$, respectively, while the UCS does not increase. As shown in Figs. 5 and 6, with increasing extrusion speed, the interface bonding of the $\mathrm{Mg} / \mathrm{Al}$ composite becomes deteriorative. To investigate the important issue whether the de-bonding or cracking occurs at interface during loading on the $\mathrm{Mg} / \mathrm{Al}$ composite rods, cross-sectional SEM micrographs of the composite rods compressed by $6 \%$ along ED are shown in Fig. 8. It can be seen that the interface of the specimen with an extrusion speed of $0.3 \mathrm{~mm} / \mathrm{s}$ was well bonded and no cracks generated at the interface. However, with increasing extrusion speed, some cracks in the diffusion layer are observed after compression. Obviously, the deteriorative bonding quality of the composite with high extrusion speeds is not beneficial to plastic deformation. Therefore, the cracking at interface is suspected to be the main reason for the slightly decreased strength of the composite rod with increasing extrusion speed. The cracking at interface is influenced by 

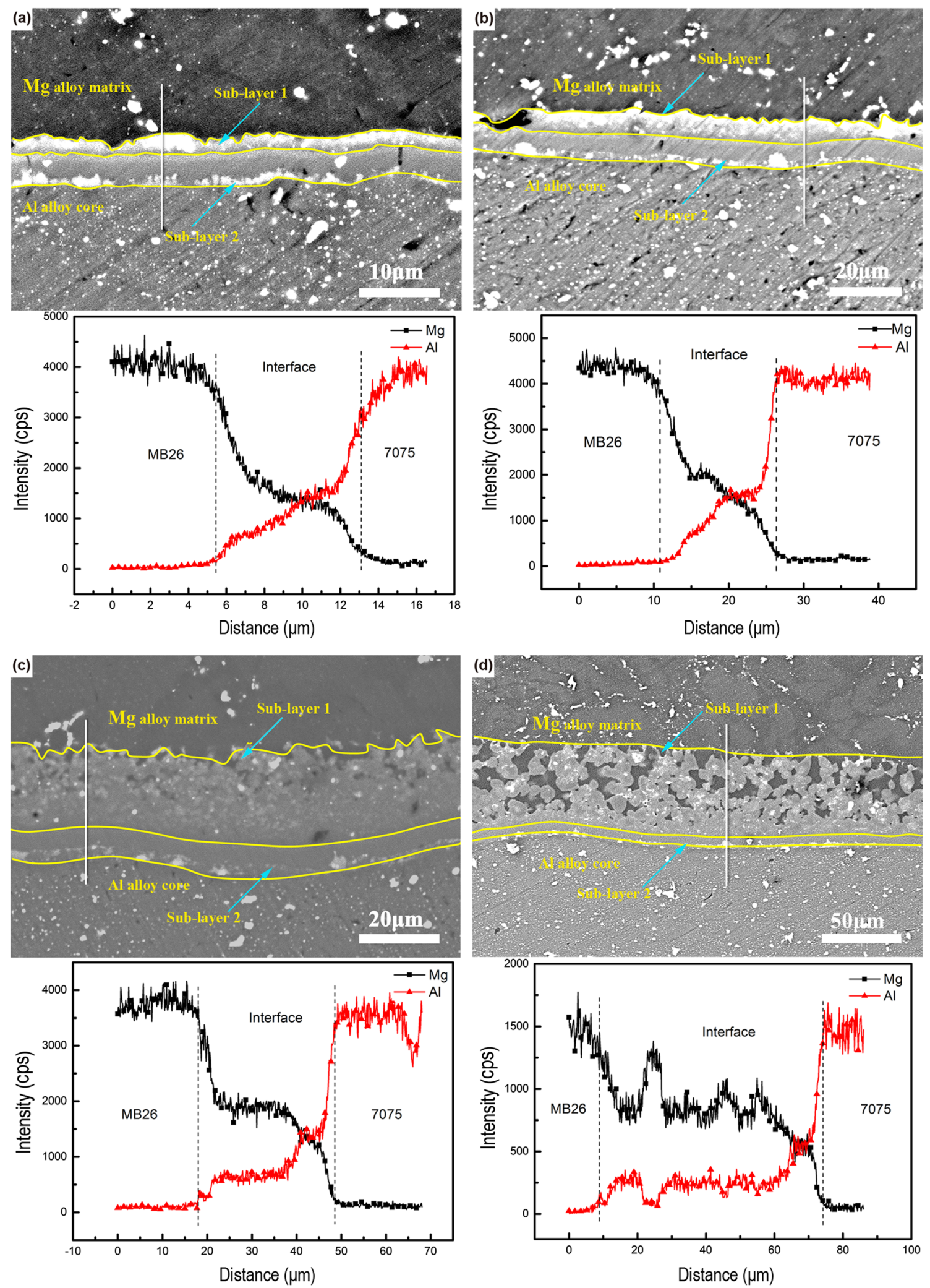

Fig. $6 \mathrm{SEM}$ images and EDS analysis of the reaction layer of the $\mathrm{Mg} / \mathrm{Al}$ composite rods at different extrusion speeds: a $0.3 \mathrm{~mm} / \mathrm{s}, \mathbf{b} 0.7 \mathrm{~mm} / \mathrm{s}$, c $1.2 \mathrm{~mm} / \mathrm{s}, \mathbf{d} 2.1 \mathrm{~mm} / \mathrm{s}$ 

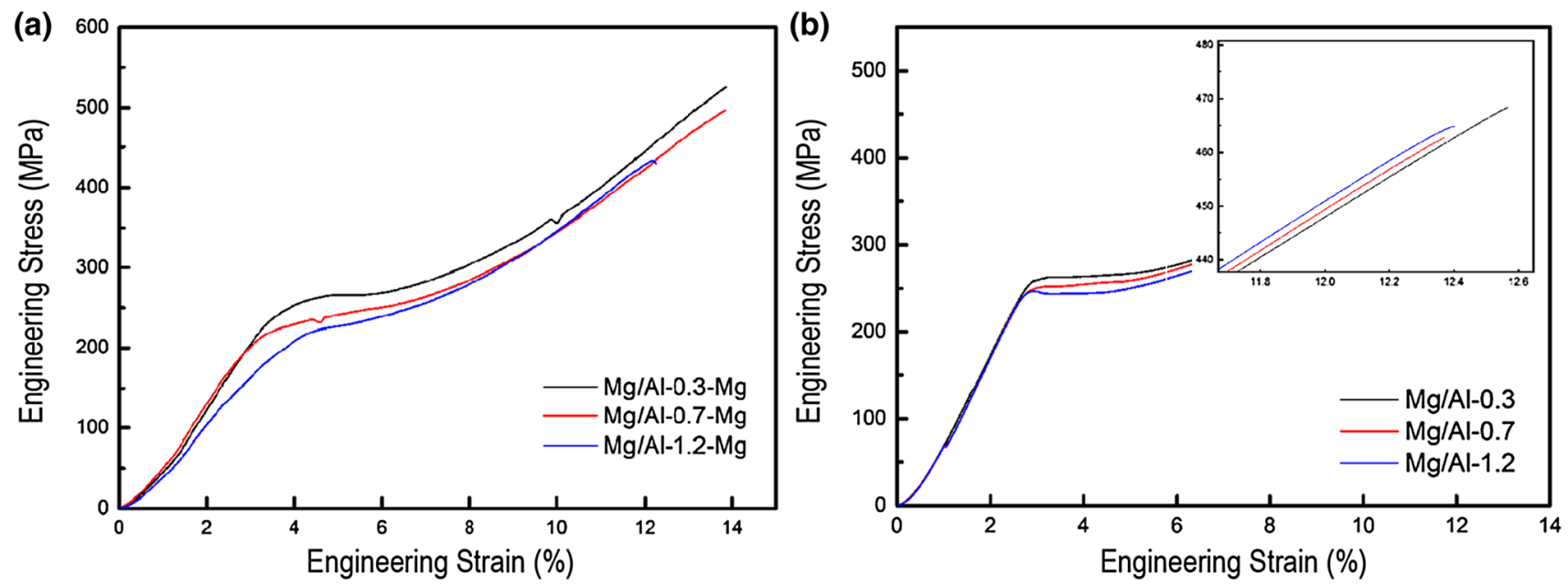

Fig. 7 Engineering stress-strain curves of the $\mathrm{Mg}$ sleeve and $\mathrm{Mg} / \mathrm{Al}$ composite rod with different extrusion speeds compressed along ED: a Mg sleeve, b $\mathrm{Mg} / \mathrm{Al}$ composite rod

Table 2 CYS, UCS and intensity of the $\mathrm{Mg} / \mathrm{Al}$ composite rods with different $V_{\mathrm{AL}}$ under compression along ED

\begin{tabular}{|c|c|c|c|c|c|c|}
\hline Samples & $\begin{array}{l}\text { Volume fractions } \\
\text { of the } \mathrm{Al}(\%)\end{array}$ & $\begin{array}{l}0.2 \% \\
\text { CYS } \\
\text { (MPa) }\end{array}$ & $\begin{array}{l}\text { UCS } \\
(\mathrm{MPa})\end{array}$ & $\begin{array}{l}\text { Density } \\
\left(\mathrm{g} / \mathrm{cm}^{3}\right)\end{array}$ & Processing method & Ref. \\
\hline $\begin{array}{l}\text { MB26 (sleeve)/ } \\
7075 \text { (core) }\end{array}$ & 6.6 & 263 & 470 & 1.88 & Co-extrusion at $0.3 \mathrm{~m} / \mathrm{s}$ & $\begin{array}{c}\text { Present } \\
\text { work }\end{array}$ \\
\hline $\begin{array}{l}\text { MB26 (sleeve) } / \\
7075 \text { (core) }\end{array}$ & 6.6 & 252 & 466 & 1.88 & Co-extrusion at $0.7 \mathrm{~m} / \mathrm{s}$ & $\begin{array}{c}\text { Present } \\
\text { work }\end{array}$ \\
\hline $\begin{array}{l}\text { MB26 (sleeve)/ } \\
7075 \text { (core) }\end{array}$ & 6.6 & 246 & 453 & 1.88 & Co-extrusion at $1.2 \mathrm{~m} / \mathrm{s}$ & $\begin{array}{c}\text { Present } \\
\text { work }\end{array}$ \\
\hline \multirow{4}{*}{$\begin{array}{l}\text { AZ31 (sleeve)/ } \\
7050 \text { (core) }\end{array}$} & 8.4 & 194 & 430 & 1.87 & \multirow{4}{*}{$\begin{array}{l}\text { Co-extrusion }+ \text { two-stage aging at } 120^{\circ} \mathrm{C} \text { for } 8 \mathrm{~h} \text { and } \\
150{ }^{\circ} \mathrm{C} \text { for } 9 \mathrm{~h}\end{array}$} & \multirow[t]{4}{*}[21,22]{} \\
\hline & 16 & $212-217$ & $445-506$ & 1.95 & & \\
\hline & 24.2 & 227 & 473 & 2.03 & & \\
\hline & 33.8 & 270 & 500 & 2.08 & & \\
\hline \multirow{2}{*}{$\begin{array}{r}7050 \text { (sleeve)/ } \\
\text { AZ31 (core) }\end{array}$} & 43.7 & 235 & 351 & 2.24 & \multirow{2}{*}{$\begin{array}{l}\text { Co-extrusion }+ \text { aging at } 120^{\circ} \mathrm{C} \text { for } 8 \mathrm{~h}+\text { annealed at } \\
400{ }^{\circ} \mathrm{C} \text { for } 63 \mathrm{~h}+\text { aged at } 150{ }^{\circ} \mathrm{C} \text { for } 9 \mathrm{~h}\end{array}$} & \multirow[t]{2}{*}[20]{} \\
\hline & 55.6 & 264 & 375 & 2.36 & & \\
\hline
\end{tabular}

the intermetallic compounds at interface and the thickness of interfacial diffusion layer [20, 40, 41].

In addition, Table 2 also shows the CYS and UCS values of some other studies on the co-extrusion of $\mathrm{Mg} / \mathrm{Al}$ composite rods [20-22]. For the AZ31 (soft sleeve)/7075 (ultra-hard core) composite rods processed by co-extrusion and two-stage aging [21, 22], when the volume fraction of $\mathrm{Al}\left(V_{\mathrm{AL}}\right)$ is at the range of $8.4 \%-24.2 \%$, the CYS of the composite rods ranged from 194 to $227 \mathrm{MPa}$. With increasing the $V_{\mathrm{AL}}$ up to $33.8 \%$, the CYS of the composite rods attains $270 \mathrm{MPa}$. Moreover, for the 7050 (ultra-hard sleeve)/AZ31 (soft core) composite rods fabricated by coextrusion, followed by aging at $120^{\circ}$ for $8 \mathrm{~h}$ and annealed

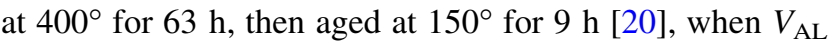
are $43.7 \%$ and $55.6 \%$, the CYS of the composite rods ranged from 235 to $264 \mathrm{MPa}$, respectively. However, in the present work, although the $V_{\mathrm{AL}}$ is only $6.6 \%$, the composite rods exhibit high CYS ranging from 246 to $263 \mathrm{MPa}$. To obtain the equal value of CYS, for the AZ31 (soft sleeve)/ 7075 (ultra-hard core) composite rods [21, 22], the $V_{\mathrm{AL}}$ must be higher than $24.2 \%$ and even close to $33.8 \%$, and for the 7050 (ultra-hard sleeve)/AZ31 (soft core) composite rods [20], the $V_{\mathrm{AL}}$ must be increased up to $55.6 \%$. The density values of composite rods listed in Table 2 infer that higher specific strength values can be achieved by co-extrusion of MB26/7075 composite rod, compared with the AZ31/7050 composite rod. 

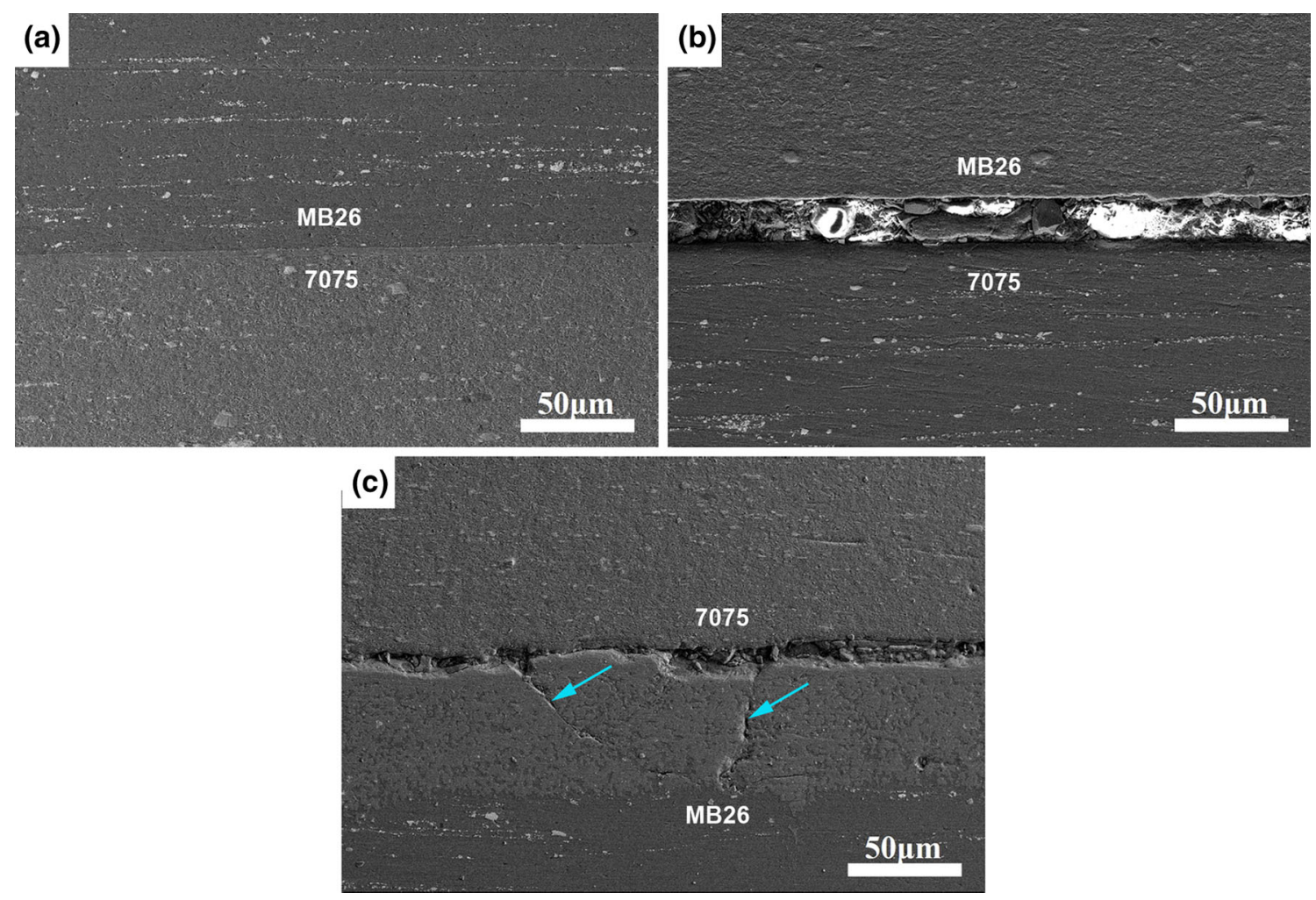

Fig. $8 \mathrm{SEM}$ micrographs of $\mathrm{Mg} / \mathrm{Al}$ composite rod compressed by $6 \%$ at elevated extrusion speeds: a $0.3 \mathrm{~mm} / \mathrm{s}, \mathbf{b} 0.7 \mathrm{~mm} / \mathrm{s}, \mathbf{c} 1.2 \mathrm{~mm} / \mathrm{s}$

\section{Conclusions}

(1) Surface quality of the Mg MB26/Al 7075 composite rod becomes deteriorative with increasing extrusion speed. This phenomenon mainly attributes to the difference in flow velocity between $\mathrm{Mg}$ sleeve and $\mathrm{Al}$ core in the process of co-extrusion.

(2) The average grain size shows a slightly growing trend, from 1.57 to $2.78 \mu \mathrm{m}$ at corresponding speeds from 0.3 to $2.1 \mathrm{~mm} / \mathrm{s}$, respectively. The typical extrusion texture of $\mathrm{Mg}$ sleeve does not change.

(3) The interface bonding becomes deteriorative with the occurrence of many voids as the extrusion speed increases. This observation is mainly due to the locally melting of interface metals. Meanwhile, the transition layer thickness increases significantly from 5.5 to $50 \mu \mathrm{m}$, consisting of much brittle intermetallic compounds such as $\mathrm{Mg}_{17} \mathrm{Al}_{12}$ and $\mathrm{Mg}_{2} \mathrm{Al}_{3}$.

(4) Although the compression mechanical behavior of Mg MB26/Al 7075 composite rod becomes deteriorative with increasing co-extrusion speed, co-extrusion is desirable to improve the specific strength of Mg MB26/Al 7075 composite rod, with a lower Al volume fraction $(6.57 \%)$, in comparison with other composite rods like AZ31/7050 (24.2\%, 33.8\%) or 7050/AZ31 (55.6\%).
Acknowledgements This work was supported by the National Natural Science Foundation of China (Grant Nos. 51301213, 51501026 and 51701034), the Basic and Advanced Research Project of CQ CSTC (Grant Nos. cstc2016jcyjA0452, cstc2017jcyjAX0775 and cstc2017jcyjAX0062), and Scientific and Technological Research Program of Chongqing Municipal Education Commission (Grant Nos. KJ1600922, KJ1600924).

\section{References}

[1] J. Zhang, S. Yan, H. Qu, Int. J. Hydrog. Energy 43, 3 (2018)

[2] L.G. Hou, T.Z. Wang, R.Z. Wu, J.H. Zhang, X.L. Li, M.L. Zhang, A.P. Dong, B.D. Sun, J. Mater. Sci. Technol. 34, 317 (2018)

[3] X.J. Wang, D.K. Xu, R.Z. Wu, X.B. Chen, Q.M. Peng, L. Jin, Y.C. Xing, Z.Q. Zhang, Y. Liu, X.H. Cheng, G. Chen, K.K. Deng, H.Y. Wang, J. Mater. Sci. Technol. 34, 245 (2018)

[4] H.J. Wu, T.Z. Wang, R.Z. Wu, L.G. Hou, J.H. Zhang, X.L. Li, M.L. Zhang, J. Mater. Process. Technol. 254, 265 (2018)

[5] K.L. Zheng, D.J. Politis, L.L. Wang, J.G. Lin, Int. J. Mach. Tools Manuf. 1, 2 (2018)

[6] H.P. Zheng, J.L. Yang, R.Z. Wu, T.Z. Wang, X.D. Ma, L.G. Hou, M.L. Zhang, S. Betsofen, B. Krit, Adv. Eng. Mater. 18, 10 (2016)

[7] K.K. Deng, J.Y. Shi, C.J. Wang, X.J. Wang, Y.W. Wu, K.B. Nie, K. Wu, Compos. Part A Appl. Sci. 43, 8 (2012)

[8] C.Z. Luo, W. Liang, Z.Q. Chen, J.J. Zhang, C.Z. Chi, F.Q. Yang, Mater. Charact. 84, 10 (2013)

[9] C. Hai, M.Y. Zheng, Rare Metal Mat. Eng. 45, 9 (2016)

[10] G.S. Huang, W. Xu, G.J. Huang, F.S. Pan, Mater. Sci. Forum 610-613, 791 (2009) 
[11] Y. Mahmoodkhani, M.A. Wells, J. Mater. Process. Technol. 232, 175 (2016)

[12] M. Paramsothy, M. Gupta, N. Srikanth, J. Compos. Mater. 42, 24 (2008)

[13] M. Paramsothy, M. Gupta, N. Srikanth, J. Compos. Mater. 42 , 13 (2008)

[14] M. Paramsothy, S.F. Hassan, N. Srikanth, M. Gupta, J. Phys. D Appl. Phys. 41, 17 (2008)

[15] M. Paramsothy, S.F. Hassan, N. Srikanth, M. Gupta, J. Compos. Mater. 44, 9 (2009)

[16] M. Paramsothy, N. Srikanth, M. Gupta, J. Alloys Compd. 461, 1 (2008)

[17] M. Paramsothy, N. Srikanth, S.F. Hassan, M. Gupta, Mater. Sci. Eng. A 494, 1 (2008)

[18] M. Thirumurugan, S.A. Rao, S. Kumaran, T.S. Rao, J. Mater. Process. Technol. 211, 10 (2011)

[19] A. Sankaran, S. Vadakke Madam, A. Nouri, M.R. Barnett, Scr. Mater. 66, 10 (2012)

[20] B. Feng, Y.C. Xin, F.L. Guo, H.H. Yu, Y. Wu, Q. Liu, Acta Mater. 120, 379 (2016)

[21] B. Feng, Y.C. Xin, R. Hong, H.H. Yu, Y. Wu, Q. Liu, Scr. Mater. 98, 56 (2015)

[22] B. Feng, Y.C. Xin, H.H. Yu, R. Hong, Q. Liu, Mater. Sci. Eng. A 675, 204 (2016)

[23] S.H. Park, B.S. You, R.K. Mishra, A.K. Sachdev, Mater. Sci. Eng. A 583, 3 (2014)

[24] C. Xu, T. Nakata, X.G. Qiao, H.S. Jiang, W.T. Sun, Y.C. Chi, M.Y. Zheng, S. Kamado, Mater. Sci. Eng. A 685, 159 (2017)

[25] H.T. Zhou, Z.D. Zhang, C.M. Liu, Q.W. Wang, Mater. Sci. Eng. A 445, 6 (2007)
[26] D. Andrzejewski, J. Jakubowicz, J. Borowski, Arch. Civ. Mech. Eng. 16, 2 (2016)

[27] S.H. Park, S.H. Kim, H.S. Kim, J. Yoon, B.S. You, J. Alloys Compd. 667, 170 (2016)

[28] H. Yu, S. Hyuk Park, B. Sun You, Y. Min Kim, H. Shun Yu, S. Soo Park, Mater. Sci. Eng. A 583, 25 (2013)

[29] Z.H. Huang, S.M. Liang, R.S. Chen, E.H. Han, J. Alloys Compd. 468, 1 (2009)

[30] N. Tahreen, D.F. Zhang, F.S. Pan, X.Q. Jiang, D.Y. Li, D.L. Chen, J. Mater. Sci. Technol. 34, 7 (2018)

[31] L.Z. Liu, X.H. Chen, F.S. Pan, A. Tang, X.L. Wang, J. Liu, S.H. Gao, Mater. Sci. Eng. A 669, 259 (2016)

[32] A. Singh, M. Watanabe, A. Kato, A.P. Tsai, Mater. Sci. Eng. A 397, 1 (2005)

[33] Y.Q. Wu, X.M. Lu, T. Shen, T. Nonferr, Metal. Soc. (Engl. Lett.) 23, 2 (2013)

[34] C.Y. Sun, Y.P. Cong, Q.D. Zhang, M.W. Fu, L. Li, J. Mater. Process. Technol. 253, 99 (2018)

[35] H. Zengin, Y. Turen, Mater. Chem. Phys. 214, 1 (2018)

[36] E. Priel, Z. Ungarish, N.U. Navi, J. Mater. Process. Technol. 236, 103 (2016)

[37] X.R. Li, W. Liang, X.G. Zhao, Y. Zhang, X.P. Fu, F.C. Liu, J. Alloys Compd. 471, 1 (2009)

[38] S.R. Agnew, J.F. Nie, Scr. Mater. 63, 7 (2010)

[39] S.G. Hong, S.H. Park, C.S. Lee, Acta Mater. 58, 18 (2010)

[40] L.M. Zhao, Z.D. Zhang, Scr. Mater. 58, 4 (2008)

[41] X.B. Liu, R.S. Chen, E.H. Han, Mater. Process. Technol. 209, 10 (2009) 